Article

\title{
Regenerable Superhydrophobic Coatings for Biomedical Fabrics
}

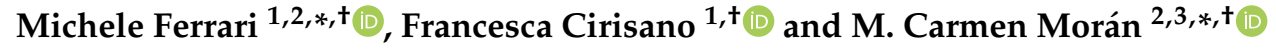 \\ 1 CNR-ICMATE Istituto di Chimica della Materia Condensata e di Tecnologie per l'Energia, via De Marini, 6, \\ 16149 Genova, Italy; francesca.cirisano@ge.icmate.cnr.it \\ 2 Institut de Nanociència i Nanotecnologia-IN2UB, Universitat de Barcelona, Avda Diagonal, 645, \\ 08028 Barcelona, Spain \\ 3 Departament de Bioquímica i Fisiologia, Secció de Fisiologia-Facultat de Farmàcia i Ciències de \\ l'Alimentació, Universitat de Barcelona, Avda. Joan XXIII, 27-31, 08028 Barcelona, Spain \\ * Correspondence: michele.ferrari@ge.icmate.cnr.it (M.F.); mcmoranb@ub.edu (M.C.M.); \\ Tel.: +39-0106-475-744 (M.F.); +34-9340-245-05 (M.C.M.) \\ + The authors dedicate this work to the victims of Coronavirus Pandemic (COVID-19).
}

Received: 2 May 2020; Accepted: 17 June 2020; Published: 20 June 2020

\begin{abstract}
Coatings with high water repellence represent a promising field for biomedical applications. Superhydrophobicity (SH) can be used for preventing adhesion, controlling cell deposition, and spreading by inhibition of adsorption processes at liquid-solid interfaces. The recyclability of medical aids like fabrics can open the way for lower cost and more environmentally-friendly solutions. In this case, two different coatings form recyclable and low global warming potential materials and green solvents have been prepared and characterized based on their wettability properties. The resulting substrates have been used for the adhesion and spreading of representative skin cell lines, both tumoral and non-tumoral, showing a strong decrease in cell viability with values < $10 \%$. The coated substrates showed a complete recovery on initial SH properties after rinsing with suitable solvents.
\end{abstract}

Keywords: cell viability; fabrics; superhydrophobicity; recyclability; wettability

\section{Introduction}

Superhydrophobic (SH) coatings have arisen in the last decade as an alternative, physico-chemical way to prevent adhesion in many fields including biomedical applications. Their use has significantly grown in this area, where, for example, cell growth, cell proliferation, or biopolymers adsorption have to be controlled, if not avoided. The common aim in the development of such material is the presence of entrapped air in the surface grooves resulting in preventing adhesion with high water repellence and delaying or hindering adsorption processes [1]. The wettability properties of such a surface are related to their high contact angle $\left(>150^{\circ}\right)$ and very low hysteresis $\left(<5^{\circ}\right)$ as a result of fakir carpet-like composite surface according to the Cassie-Baxter model [2], which advanced the previous work of Wenzel [3] in defining the role of surface morphology and chemistry in determining low wetting properties of bird feathers. These characteristics are wide spread in Nature both in plants and animals with different purposes ranging from low friction, self-cleaning, or antifouling behaviors.

The influence of coating surface energy on biofilm adhesion is often a matter of contradictory work indicating that both high or low energy surface decrease bacterial adhesion as described in Ref. [4], where the use of DLVO theory is combined with the effect of substrates at different surface energies on bacterial adhesion. Surface features like morphology, roughness, and chemistry and their relationship with hydrophobicity and cell adhesion in polydimethylsiloxane (PDMS) nanocomposites 
loaded with titanium dioxide $\left(\mathrm{TiO}_{2}\right)$ nanoparticles have been investigated in Ref. [5] showing the influence of surface chemistry in reducing cell viability in samples at a higher $\mathrm{TiO}_{2}$ ratio.

The growing potential of SH coatings or materials repelling bacteria settlement or biological fluids with consequent inflammation or infection is studied in Ref. [6]. Polyhexamethylene biguanide has been used in layer by layer application on cotton fabrics, followed by inclusion of an epoxy alkane/epoxy cross-linker. With high contact angle and good shedding angle, these textiles were shown to inhibit biofilm attachment of about $70 \%$.

Plasma CVD and UV irradiation have been used to prepare superhydrophobic/philic surfaces as a cell culture scaffold [7]. The adhesion of the cells takes place in a very selective way; in fact, they were arranged in circular shapes corresponding to the fabricated micro pattern. Cell adhesion and spreading on modified surfaces seems to be influenced by contact time on the superhydrophobic surface, while cell proliferation rapidly starts after seeding on the superhydrophilic surface.

Proteins adsorbed preferentially on the flat hydrophilic surface than on the flat hydrophobic one. The influence of the composition of poly(dimethylsiloxane) (PDMS) on different types of mammalian cell adhesion and proliferation [8] was comparable to the behavior on tissue culture-treated polystyrene for most of the cell lines growing at similar rates on PDMS substrates and not depending on substrate stiffness in a wide range of Young's moduli.

In the biomedical field, the malfunctioning of devices is often caused by the uncontrolled adhesion of cells onto synthetic surfaces requiring the control of cell adhesion on artificial surfaces. Cell-resistant polymer coatings like poly ethyleneglycol and zwitterionic polymers have successfully been introduced onto a wide range of surfaces by appropriate immobilization techniques. The advantage of this method is that it can be applied to any material surfaces, including superhydrophobic surfaces. Moreover, it is known that polydopamine-coated surfaces show excellent cell-adhesive properties. Polydopamine-coated superhydrophobic surfaces could then provide an efficient platform for cell adhesion control [9].

Admicellar polymerization (ADPM) has been employed to form thin polystyrene film on cotton [10], improving the coverage by divinylbenzene (DVB) as cross-linking agent. Also, the same technique has been exploited for hydrophobizing cotton fabrics [11] studying the effect of ethanol and methanol on styrene ADPM on polymerization time. SEM characterization revealed ultrathin layers of polystyrene on cotton. The hydrophobicity was tested with wettability and durability investigations finding a moderate water-repellent treatment comparable with stearic acid melamine resins based commercial products.

Hydrophobic and hydrophilic FEP Teflon were compared in Ref. [12] for adhesion and spreading of human fibroblasts on untreated FEP-Teflon and tissue culture polystyrene (TCPS). Superhydrophobic FEP-Teflon was prepared by ion etching followed by oxygen glow-discharge for getting superhydrophobicity. Compared to untreated FEP-Teflon, the treatments resulted in a significant increased spread of human skin fibroblasts on hydrophilic FEP-Teflon, while the SH version showed an opposite behavior, but on TCPS spreading was higher as compared to FEP-Teflon and not so different from hydrophilic FEP-Teflon.

Superhydrophobic surfaces can be prepared by the combined use of low energy, hydrophobic coatings and nanoparticles inducing a hierarchical roughness at a nano-micro scale. Although this technology has been used in a wide range of materials, there is little evidence in the literature that describes the preparation of superhydrophobic surfaces on textile materials. Recent studies carried out in our labs have allowed establishing the basis of the preparation and characterization of surfaces and their applicability in cell culture conditions [13].

When determining the in vitro biocompatibility of a biomaterial, it mainly depends on its superficial properties, such as rigidity, surface load, chemical structure, functionality, roughness, and moisturizing [14]. Controlling the wettability of a material surface is crucial for various applications in industry, agriculture, and daily life. For biological applications, it is even more important, since the wettability directly governs the interfacial behavior of cells and biomolecules on the material surface. The interactions of cells with receptors and surfaces is fundamental, for instance, for disease detection 
and anti-infection therapy, especially those materials with good reversibility, whose interactions with cells can be switched on or off, to capture or remove cells before the next assay [15].

The 3Rs concept, reduce, reuse and recycle, is a well-known approach that is important in the production and consumption fields. It promotes the use of fewer resources minimizing new resources, re-using materials more than once in their original form, and converting waste materials into new products by physical and chemical processes [16].

This work is aimed at the preparation of cell-resistant textile fabrics with good reversibility by superhydrophobic modification. On the basis approach known as 3Rs, two different surfaces based on polyester textile were prepared from environmentally-friendly and recyclable materials with the aim of providing a low cost, sustainable solution, with potential application to large surfaces. Superhydrophobic modification was performed by mixed organic-inorganic coating with nanoparticles. Changes on viability of representative skin cell lines induced by these two different substrates have been evaluated and compared. The effect of cell deposition formation on the wettability properties and their possible recovery under mild conditions, if modified, has also been determined.

\section{Materials and Methods}

\subsection{Materials}

Polyester (PES) textile substrates were kindly provided by wfk Testgewebe-Test Materials and Concepts (Brüggen-Bracht, Germany). Commercially available fluoropolymer (Surface Energy $15 \mathrm{mN} / \mathrm{m}$ ) in methoxy-nonafluorobutane (low (320) global warming potential * and zero Ozone Depletion Potential $\left.{ }^{* *}\right)$ ) was used as received. Fumed silica was purchased from Degussa (Hannover, Germany) with primary particles about 5-30 nanometers in size. Polystyrene available for packaging (PS Surface energy $40 \mathrm{mN} / \mathrm{m}$ )) was used as received. Polytetrafluoroethylene (PTFE Surface energy $20 \mathrm{mN} / \mathrm{m}$ ) powder, average diameter of the powder is $1 \mu \mathrm{m}$, and ethyl acetate (EtOAc), purity grade $>99 \%$, were supplied by Sigma-Aldrich (Darmstadt, Germany) and used as received. $\left({ }^{*}\right.$ GWP-100 year Integration Time Horizon $($ ITH $) * *$ CFC-11 $\left.=1.0\right)$

2,5-Diphenyl-3-(4,5-dimethyl-2-thiazolyl) tetrazolium bromide (MTT) and dimethylsulfoxide (DMSO) were obtained from Sigma-Aldrich (St. Louis, MO, USA). Dulbecco's Modified Eagle's Medium (DMEM), fetal bovine serum (FBS), L-glutamine solution (200 mM), penicillin-streptomycin solution $(10,000 \mathrm{U} / \mathrm{mL}$ penicillin and $10 \mathrm{mg} / \mathrm{mL}$ streptomycin), trypsin-EDTA solution $(170,000 \mathrm{U} / \mathrm{L}$ trypsin and $0.2 \mathrm{~g} / \mathrm{L}$ EDTA), and phosphate buffered saline (PBS), were purchased from Lonza (Verviers, Belgium). The $75-\mathrm{cm}^{2}$ flasks and 24-well cell culture plates were obtained from TPP (Trasadingen, Switzerland). All other reagents were of analytical grade.

\subsection{Methods}

\subsubsection{Surface Preparation and Characterization}

Before SH functionalization, the PES fabrics were cut from $10 \mathrm{~cm} \times 10 \mathrm{~cm}$ samples as received to $1 \mathrm{~cm}$ of diameter to be inserted in 24-well TCPS plates. In order to produce superhydrophobic (SHS) surfaces, different formulation were applied on fabrics by spray coating technique for few a seconds. The first formulation (SHS1) was prepared by the dispersion of fumed silica nanoparticles in a concentration range $0.5-2 \mathrm{~g} / \mathrm{L}$ in fluoropolymer blend [17] with methoxy-nonafluorobutane as solvent, the superhydrophobic surface (SHS2) was obtained starting from dispersion obtained by mixing PS dissolved in EtOAc in a concentration range $0.5-2 \mathrm{~g} / \mathrm{L}$ and PTFE powder (nominal diameter 1 micron) at fixed concentration of $40 \mathrm{~g} / \mathrm{L}$. The as-prepared coatings have been rinsed in water to assess the high water repellence and remove the eventual residuals that could affect the cell proliferation.

Once dried, surface wettability was investigated by contact angle (CA) by drop shape method by ASTRAview tensiometer [18] allowing real time drop volume control up to tens of $\mu \mathrm{L}$ for hysteresis studies (advancing-receding CA) and up to 15 frames/s of frame grabbing. Drops of 
about $5 \mu \mathrm{L}$ were deposited on coated and uncoated samples and contact angle was measured up to spreading equilibrium.

SEM observations included morphology studies for both coated and uncoated fabric samples with energy-dispersive X-ray spectroscopy (EDS) were done. From EDS, elemental maps were acquired for following material distribution $(\mathrm{C}, \mathrm{F}, \mathrm{O}$, and $\mathrm{Si}$ ) along the fibers and to evaluate homogeneity distribution in the area under investigation.

The surface structure of samples was investigated by 3D Confocal and Interferometric Profilometry (Sensofar S-NEOX, Barcelona, Spain) in order to evaluate the roughness and to acquire confocal image. The profilometry was chosen to permit large surfaces scan, for its ease and fast non-destructive use. The profilometry surface characterization were performed according to the standard ISO 25178.

\subsubsection{Cell Cultures}

The murine Swiss albino fibroblast (3T3), the immortal human keratinocytes (HaCaT), and the human squamous carcinoma cells (A431) were grown in DMEM medium $(4.5 \mathrm{~g} / \mathrm{L}$ glucose) supplemented with $10 \%(v / v)$ FBS, $1 \%(v / v)$ L-glutamine, and $1 \%(v / v)$ antibiotic at $37^{\circ} \mathrm{C}$ and $5 \% \mathrm{CO}_{2}$. Cells were cultured in $75-\mathrm{cm}^{2}$ culture flasks and were routinely split when cells were approximately $80 \%$ confluent.

\subsubsection{Cell Interactions with Surfaces}

Cell viability was evaluated on both solid surfaces and textile fabrics. Thus, conventional 24-well tissue culture polystyrene (TCPS) plates were used. Concerning the textile fabrics, PES fabrics of $1 \mathrm{~cm}$ of diameter were sterilized in humid vapor $\left(121^{\circ} \mathrm{C}, 1 \mathrm{~atm}\right)$ dried at $60^{\circ} \mathrm{C}$, and properly prepared according to the above described coating methodology. Then, the modified substrates were placed in individual wells of 24-well TCPS plates.

To assess successful sterilization of TCPS plates in the presence of any type of textile substrates, plates were pre-treated before any cell involving assays were conducted. The pre-treatment consisted in the sterilization by UV procedure during $45 \mathrm{~min}$, based on the protocol described by Sharma [19]. For comparative purposes, TCPS plates in the absence of any type of textile substrates were subjected to the same treatment.

$3 \mathrm{~T} 3$ and $\mathrm{HaCaT}$ cells $\left(1 \times 10^{5}\right.$ cells $\left./ \mathrm{mL}\right)$ and A431 cells $\left(5 \times 10^{4}\right.$ cells $\left./ \mathrm{mL}\right)$ were seeded into 24-well cell culture plates in the absence or presence of fabrics. In order to ensure that the cell attachment was not decreased due to medium culture repellence and sample floating, the PES samples were fixed onto the bottom of the culture wells. Cells on uncoated textile substrates constitute cells control in textile substrates. After incubation for $24 \mathrm{~h}$ under $5 \% \mathrm{CO}_{2}$ at $37^{\circ} \mathrm{C}$, the spent medium was replaced with $500 \mu \mathrm{L}$ of fresh medium supplemented with $5 \%$ FBS. After a subsequent $24 \mathrm{~h}$, cell viability was determined by the MTT assay. In this assay, living cells reduce the yellow tetrazolium salt MTT to insoluble purple formazan crystals, according to the protocol described for the first time by Mossman et al. [20,21]. Thus, media was removed and $500 \mu \mathrm{L}$ of MTT in PBS $(5 \mathrm{mg} / \mathrm{mL})$ diluted 1:10 in medium without FBS and phenol red was then added to the cells. The plates were incubated for a further $3 \mathrm{~h}$, after which the medium was removed. Thereafter, $500 \mu \mathrm{L}$ of DMSO was added to each well to dissolve the purple formazan product. Plates were then placed in a micro titre-plate shaker for $10 \mathrm{~min}$ at room temperature and the absorbance of the resulting solutions was recovered in a 96-plate cell culture plate and measured at $550 \mathrm{~nm}$ using a Bio-Rad 550 microplate reader. The effect of each surface on viability was calculated as the percentage of tetrazolium salt reduction by viable cells against the untreated cell control (cells in uncoated TCPS plates).

\subsubsection{Recovery of the Substrates Properties after Interaction with Cells}

After the corresponding treatments involved in the measurement of cell viability, the surfaces were washed with distillate water and dried at a mild temperature. Because of the wetting dynamics, contact angle of the water drops over the surfaces was measured offline from video frames. 
In the case of substrates in which wettability was modified, the surfaces were treated with distilled water, water/acetic acid solution (1:1) or pure acetic acid. The surfaces were incubated in the solutions in 5-min sonication cycles and their wettability was determined.

\subsubsection{Statistical Analyses}

All experiments were performed at least three times on independent occasions unless otherwise stated. Results are expressed as means \pm standard deviation. One-way analysis of variance (ANOVA) was used to determine statistical differences between data sets, following the Scheffé post-hoc tests for multiple comparisons. The IBM SPSS Statistics software Version 26.0 was used to perform statistical analyses. Differences were considered statistically significant at $p<0.001$. Significant differences were illustrated in the figure with asterisk or other superscript symbols.

\section{Results and Discussion}

\subsection{Physicochemical Characterization of the Coated Surfaces}

The studied surfaces were prepared from recyclable and environmentally-friendly materials with the aim of providing a low cost, sustainable solution, with potential application to large surfaces [22].

Superhydrophobic modification was performed by organic-inorganic mixed coating with fluoropolymer blend in combination with fumed silica nanoparticles (SHS1) and by polystyrene solution with dispersed polytetrafluoroethylene particles (SHS2). To avoid side effects on cells, all the materials have been selected and used according to the safety data sheet provided. Moreover, in the case of fluoro-based coatings, they contain non-toxic and inert compounds insoluble in water, without a further release detectable, in case, by adsorbing at liquid-solid interface then influencing the wettability properties. In case of coatings based on polystyrene, it is used on conventional TCPS (Tissue Culture Polystyrene) plates, as a substrate where cells come and grow completely in contact with the surface. The highest hydrophobicity and insolubility in water of polytetrafluoroethylene avoid the contact with the water-based medium used in the experiments.

Since in such conditions, hydrophobicity drops typically roll off the SHS surface, CA was then measured with the drop still hanging from the capillary tip (Figure 1). Hysteresis measured by advancing-receding technique was less than $5^{\circ}$ for SHS, while for uncoated fabric samples complete wettability was observed. Moreover, the hysteresis value address to the absence of release of soluble substances from the coatings affecting, by adsorption, the wettability properties.

\subsection{Cell Interactions with Surfaces}

The interactions between the biological systems and the new materials are of fundamental importance for the study of biomaterials. In vitro cell culture assays are of principal interest to assess the biocompatibility of materials. Also, such initial in vitro analyses provide an excellent way to screen materials before performing in-depth in vivo-based analyses. Among the putative cell lines suitable to perform the present study, commercially available cell lines that include representative cells of the different layers of the skin were chosen. The function of the skin includes acting a barrier providing protection from physical, chemical and microbiological agents [23]. Keratinocytes represent $95 \%$ of the epidermal cells, acting as structural and barrier function of the epidermis. Their role on the skin inflammatory and immunological responses, and wound repair are well recognized. The spontaneously immortalized human keratinocytes $\mathrm{HaCaT}$ cell line from adult skin has been proposed as a model for the study of keratinocytes functions [24]. This work includes another keratinocytes with tumoral characteristics such as squamous cell carcinoma (SCC) through the A431 cell line, considering that SCC is by far the most common skin cancer, and actually is more common than any other form of cancer [25]. Fibroblasts (3T3 cell line) have become one of the most common non-epithelial cell line used in in vitro studies on general cytotoxicity and biocompatibility studies. Swiss albino mouse fibroblasts are readily available, show a well-defined protocol, and are representative of a physiologic model cell line [26]. 

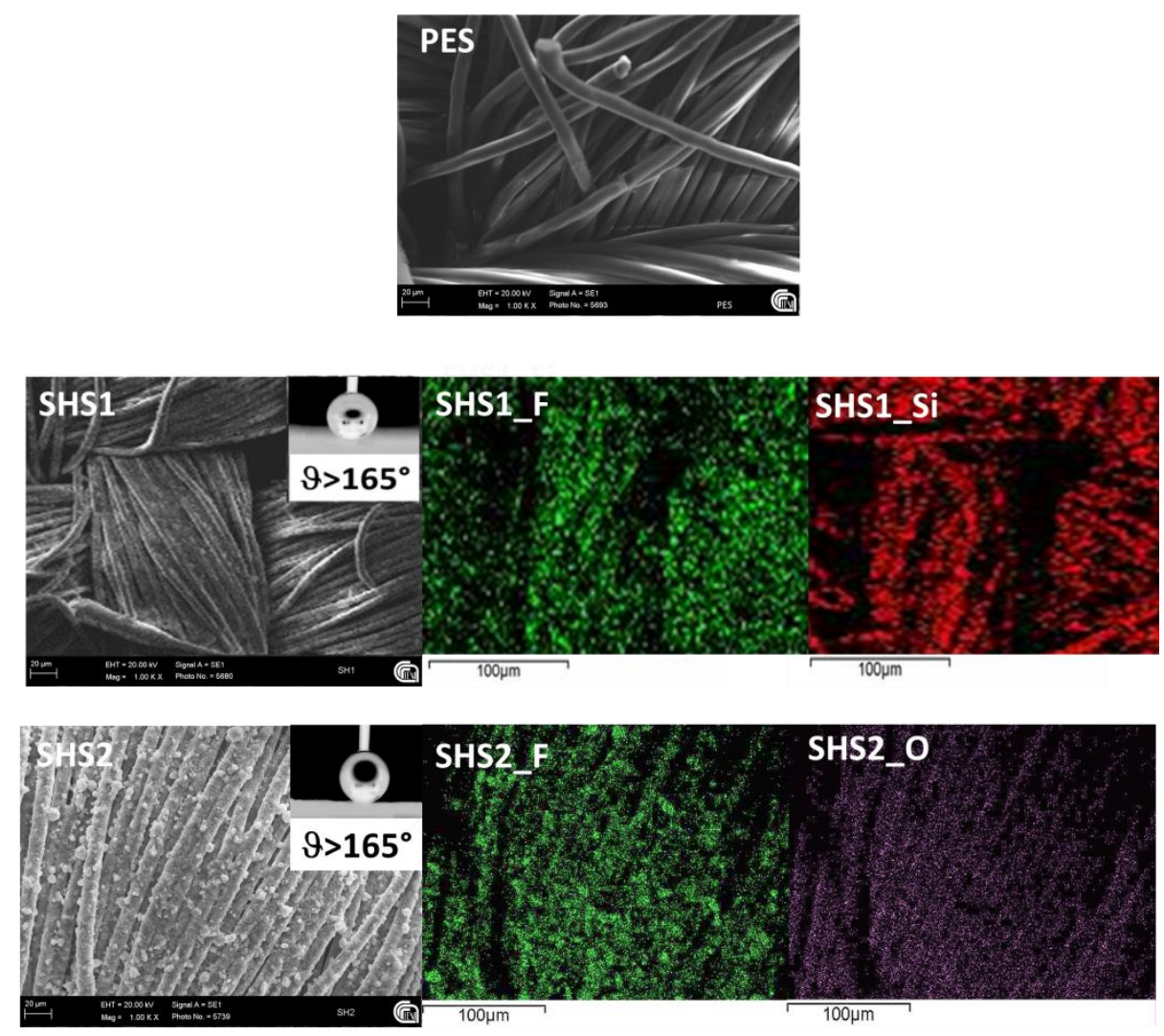

Figure 1. Surface morphology (1000x) of uncoated and coated PES and contact angle (degrees), and EDS maps for F (green), O (purple) and Si (red) of PES fabrics with 2 different superhydrophobic $(\mathrm{SH})$ treatments.

Modified surfaces should not be toxic in nature due to the properties of both PES fabric as well as coating materials. However, the induced superhydrophobicity aims to the decrease of cells adhesion and spreading. Most adherent cells, like fibroblasts and epithelial cells are anchorage dependent, requiring integrin-mediated signaling to stimulate cell-cycle progression and promote cell survival. Loss of integrin-mediated signaling can cause cell death, which can be determined by using the conventional MTT colorimetric method as a measure of the changes on the metabolic activity of cells upon incubation in the presence of the different substrates [13,21].

Cellular viability was reduced in any textile substrate, either in the absence or presence of coating, compared to standard TCPS conditions, which constitutes the $100 \%$ of cellular viability (Figure 2). In all cases, differences $(p<0.001)$ were found between TCPS and the other substrates, independently of the cell type. Experiments carried out in native PES substratum, as well as other modifications provide feasibility values ranging from 7.1 to $8.0 \%$ (3T3), 6.8 to $8.3 \%$ (HaCaT), and $5.4-8.1 \%$ (A431) with mean values ranged between 7.6 (3T3), 7.1 (HaCaT), and 6.4 (A431).

In vitro cell viability and cytotoxicity assays with cultured cell have demonstrated to be useful for the drug screening or cytotoxicity tests of chemicals. These in vitro assays are based on the alteration of some fundamental cell functions such as membrane permeability, enzymatic activity, ATP production, and cell adherence and morphology, among others [27]. Due to the biocompatible properties of both the compounds used to modify fabrics as well as the own substrate, the lack of cell viability may be related to some limitations in adhesion, restrictions of cell attachment, and spreading under the assayed conditions. 
3 T3 $\square$ HaCaT $\square$ A431

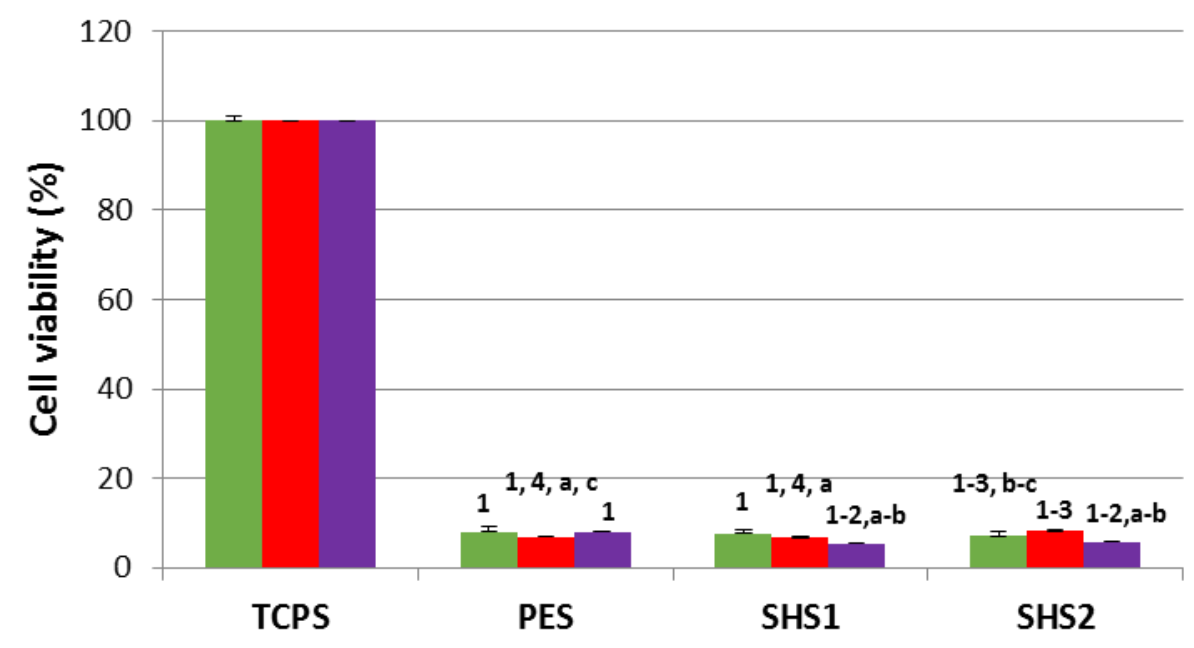

Figure 2. Relative viability of cell lines on unmodified and modified substrates, for $24 \mathrm{~h}$, determined by MTT assay. The data corresponds to the average of three independent experiments \pm standard deviation. Letter indicates significant differences $(p<0.001)$ between the three cell lines for the same substrate (a: 3T3; b: HaCaT and c: A431). Number indicates significant differences $(p<0.001)$ between the four substrates for the same cell line (1: TCPS; 2: PES; 3: SHS1; and 4: SHS2).

Taking into account cell viability values using native PES substrate, significant differences between non-tumoral cell lines (3T3 and $\mathrm{HaCaT}$ cell lines) and both types of keratinocytes (HaCaT and A431 cell lines) were found. The procedure to prepare SHS2 substrate allows us to establish significant differences $(p<0.001)$ between the uncoated PES substrate for all the cell lines. Moreover, in the case of A431 cell line, significant differences with SHS1 were also found. These results demonstrated that the A431 seems to be more sensitive to the coating procedure of the fabrics, independently of the coating type, when compared with native PES. However, in the case of non-tumoral cell lines, the modification of PES using SHS2 conditions results in being more favorable than that obtained with SHS1.

The effect of different coating (either SHS1 or SHS2) demonstrated to induce differences $(p<0.001)$ in cell responses when the two non-tumoral cell lines ( $3 \mathrm{~T} 3$ and HaCaT) were considered. When the coated SHS1 substrate was considered, differences between fibroblast (3T3 cell line) and the two keratinocyte cells lines (HaCaT and A431 cell lines) were found. In the case of SHS2 substrate, differences between all cell lines were found.

The obtained results are in agreement with our working hypothesis through which $\mathrm{SH}$ surfaces could be effective in decreasing cell adhesion.

\subsection{Recovery of the Substrates Properties after Interaction with Cells}

One of the objectives of this work was to evaluate the durability of the superhydrophobic character of these surfaces after interaction with cells and their possible recovery, in the event that they were modified. Determining wettability by measurement of the contact angle has allowed the evaluation of the hydrophilic/hydrophobic nature of the surfaces after their interaction with the cells. Contact angle of the water drops over the surfaces was measured offline from video frames and summarized in Figure 3. 


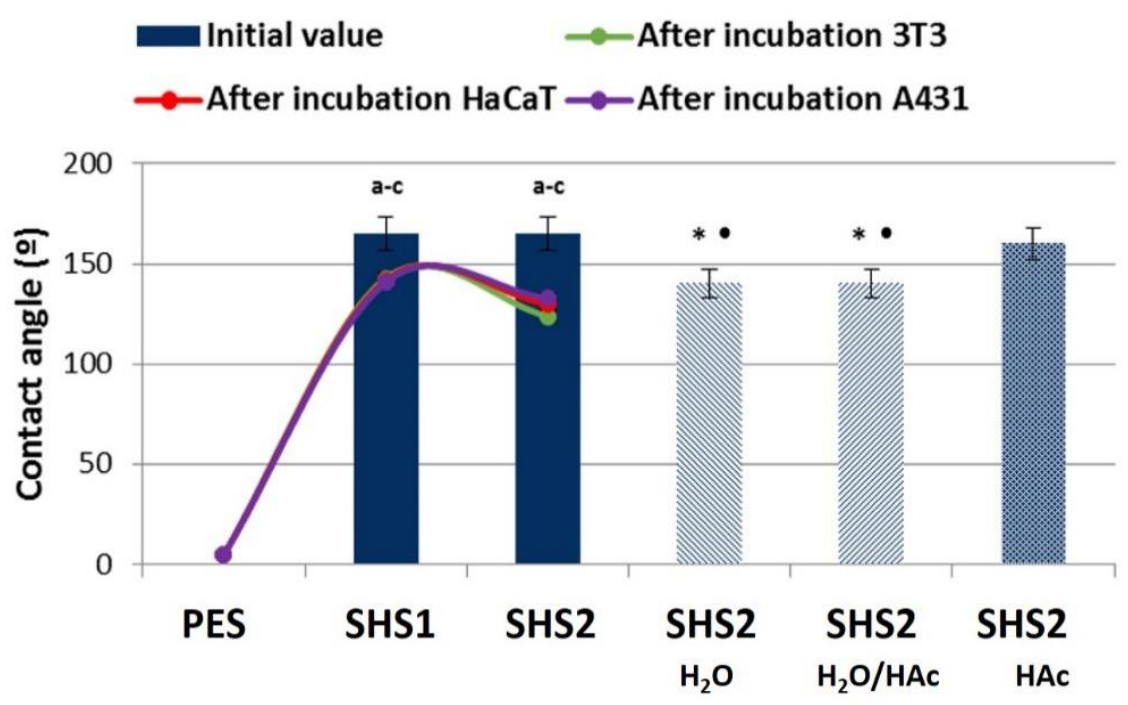

Figure 3. Influence of cell incubation on wettability of the substrates determined by drop shape method. The data corresponds to the average of three independent experiments \pm standard deviation. Letter indicates significant differences $(p<0.001)$ between the substrate before and after incubation with the three cell lines (a: 3T3; b: HaCaT; and c: A431). ${ }^{*} p<0.001$ indicates significant differences between SHS2 before the incubation with cells and $\bullet p<0.001$ indicates significant differences between the different treatments and the treatment with HAc.

The variations in the values of the contact angle are function of treatment done on the textile substrate. Thus, small modifications were made in the case of the native PES, presenting total wettability after incubation with cells. No significant differences between contact angle values before and after the incubation with cells were found.

Deposition of water on the textile substrate modified with silica nanoparticles (SHS1) showed a slight decrease on the contact angle, without alteration of their superhydrophobic properties. Indeed, the lower surface energy of the fluoropolymer blend and the smaller size of the particles address a combined effect of surface chemistry and surface morphology. This is quite evident also in the second coating where determination of the contact angle on PS modified substrate with PTFE nanoparticles (SHS2) exhibited contact angle values above $120^{\circ}$, but losing their superhydrophobic characteristics after the incubation with cells. Given the structure of the coating as reported from SEM image in Figure 1 with the layer covering homogeneously the fabric yarns, the significant differences in the wettability, reported in Figure 3, account for a coating organization in which the particles are covered by the polymer. Unfortunately, due to the high heterogeneity of the fabric yarns, it was not possible to determine with reliability the surface roughness of the coated fabric and we can only report the multi scale surface roughness value of the coating deposited on glass being SHS1 for $2-5 \mu \mathrm{m}$ and SHS2 for 70-200 nm (Figure 4). For both substrates, significant differences $(p<0.001)$ between contact angle values before and after the incubation with cells were found.

With the aim of recovering the superhydrophobic properties of the SHS2 substrates, the surfaces were treated with solutions with very different characteristics in terms of their properties as solvents and $\mathrm{pH}$ [28]. Here pure, distilled water (dielectric constant $\left(\varepsilon_{\mathrm{r}}\right) 80$ and $\mathrm{pH} 7$ ), water/acetic acid solution (1:1) (with values of $\varepsilon_{\mathrm{r}} 56$ and $\mathrm{pH}$ 5), and pure acetic acid $\left(\varepsilon_{\mathrm{r}} 6.15\right.$ and $\left.\mathrm{pH} 2.4\right)$ was used. The surfaces were incubated in the solutions in 5-minute sonication cycles and their wettability was determined (Figure 3). The recovery of superhydrophobic properties was observed after treatment with pure acetic acid. Differences $(p<0.001)$ between the contact angle values for intermediate treatments (either water or water/acetic acid mixture) and either the native SHS2 or after treatment with pure acetic acid were found. The drop does not stick on the substrate and rolls off the surface as a result of the recovered low adhesion (Hysteresis $<5^{\circ}$ ). 
SHS1
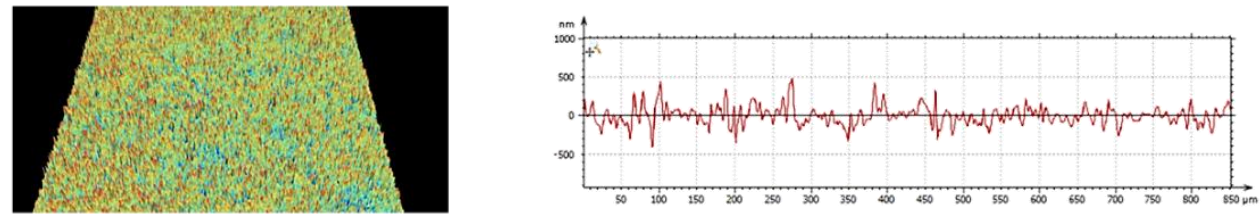

SHS2

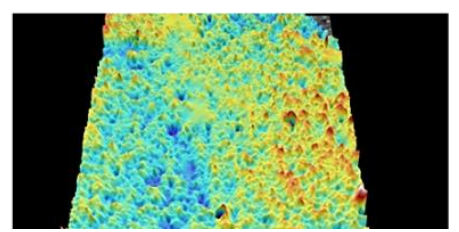

(a)

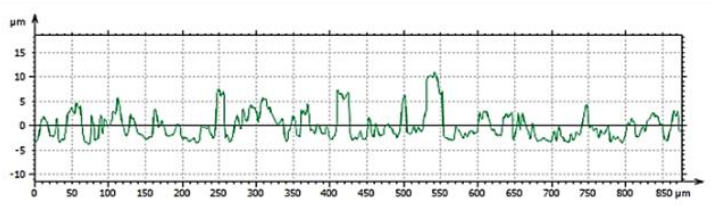

(b)

Figure 4. Representative ((a) 3D images of the two superhydrophobic fabrics (b) relative linear profilometry indicating the different roughness scales).

\section{Conclusions}

In this work, highly water-repellent coatings for biomedical purposes made of recyclable materials have been investigated. The obtained results suggest that the surfaces with the proposed modifications are effective in decreasing cell adhesion. The features of the proposed fabrics make them appropriate to avoid cell adhesion and spreading for application in which non-adhesive properties would be required.

These studies have a direct impact on the determination of the hydrophobic/superhydrophobic nature of these surfaces after interaction with cells. After contact with cells, the cell deposition residuals have been removed and the initial properties have been totally restored by means of a gentle treatment with acetic acid, which makes it possible to use it for further applications. Future developments could include the application of this method to a wider range of fabrics with different fiber composition and yarn structure.

Author Contributions: M.F. and M.C.M. conceived the experiments; F.C. and M.F. performed surface preparation, wettability, and surface analysis studies, and analyzed the experiments; M.C.M. performed the cell viability studies and analyzed the experiments; M.C.M. and M.F. wrote the manuscript. All authors discussed the results and commented on the manuscript. All authors have read and agreed to the published version of the manuscript.

Funding: This research received no external funding.

Acknowledgments: This work was conceived in the framework of the Cooperation Agreement between Faculty of Pharmacy and Food Science (UB)-Institute for Chemistry of Condensed Matter and Technologies for Energy (ICMATE-CNR) (Codi GREC 18407, 2018-2021). M.C.M. and M.F. acknowledge the support of UB-Mobility program (OMPI-PR 1493, 2017-2018 and 2018-2019 calls) for type A1 and type A2 grants, respectively.

Conflicts of Interest: The authors declare no conflict of interest.

\section{References}

1. Falde, E.J.; Yohe, S.T.; Yolonda, L.; Grinstaff, M.W. Superhydrophobic materials for biomedical applications. Biomaterials 2016, 104, 87-103. [CrossRef]

2. Cassie, A.B.D.; Baxter, S. Wettability of porous surfaces. Trans. Faraday Soc. 1944, 40, 546-551. [CrossRef]

3. Wenzel, R.N. Resistance of solid surfaces to wetting by water. J. Ind. Eng. Chem. 1936, 28, 988-994. [CrossRef]

4. Liu, Y.; Zhao, Q. Influence of surface energy of modified surfaces on bacterialadhesion. Biophys. Chem. 2005, 117, 39-45. [CrossRef]

5. Yousefi, S.Z.; Tabatabaei-Panah, P.S.; Seyfib, J. Emphasizing the role of surface chemistry on hydrophobicity and cell adhesion behavior of polydimethylsiloxane/ $\mathrm{TiO}_{2}$ nanocomposite films. Colloid Surf. B 2018, 167, 492-498. [CrossRef]

6. Patil, A.J.; Zhao, Y.; Liu, X.; Wang, X. Durable superhydrophobic andantimicrobial cotton fabrics prepared by electrostatic assembly of polyhexamethylene biguanide and subsequent hydrophobization. Text. Res. J. 2018, 88, 1788-1799. [CrossRef] 
7. Ishizaki, T.; Saito, N.; Takai, O. Correlation of cell adhesive behaviors on superhydrophobic, superhydrophilic, and micropatterned superhydrophobic/superhydrophilic surfaces to their surface chemistry. Langmuir 2010, 26, 8147-8154. [CrossRef]

8. Lee, J.N.; Jiang, X.; Ryan, D.; Whitesides, G.M. Compatibility of mammalian cells on surfaces of poly(dimethylsiloxane). Langmuir 2004, 20, 11684-11691. [CrossRef]

9. Kang, S.M.; Choi, I.S. Control of cell adhesion on a superhydrophobic surface by polydopamine coating. Bull. Korean Chem. Soc. 2013, 34, 2525. [CrossRef]

10. Pongprayoon, T.; Yanumet, N.; O’Rear, E.A.; Alvarez, W.E.; Resasco, D.E. Surface characterization of cotton coated by a thin film of polystyrene with and without a cross-linking agent. J. Colloid Interf. Sci. 2005, 281, 307-315. [CrossRef]

11. Khushalini, U.; Shukla, N.; Ramchandra, S. Enhancement of cotton hydrophobicity through modified styrene admicellar polymerization. IJFTR 2018, 43, 336-343.

12. Busscher, H.J.; Stokroos, I.; Golverdingen, J.G.; Schakenraad, J.M. Adhesion and spreading of human fibroblasts on superhydrophobic Fep-Teflon. Celsl Mater. 1991, 1, 5.

13. Morán, M.C.; Ruano, G.; Cirisano, F.; Ferrari, M. Mammalian cell viability on hydrophobic and superhydrophobic fabrics. Mater. Sci. Eng. C 2019, 99, 241-247. [CrossRef]

14. Ferrari, M.; Cirisano, F.; Morán, M.C. Mammalian cell behavior on hydrophobic substrates: Influence of surface properties. Coll. Interfaces 2019, 3, 48. [CrossRef]

15. Sun, T.; Qing, G. Biomimetic smart interface materials for biological applications. Adv. Mater. 2011, 12, H57-H77. [CrossRef]

16. European Commission. Communication from the Commission to the Council, the European Parliament, the European Economic and Social Committee and The Committee of the Regions-Taking Sustainable Use of Resources forward-A Thematic Strategy on the Prevention and Recycling of Waste; European Commission: Brussels, Belgium, 2000.

17. Ferrari, M.; Ravera, F.; Liggieri, L. Preparation of a superhydrophobic surface by mixed inorganic-organic coating. Appl. Phys. Lett. 2006, 88, 203125. [CrossRef]

18. Liggieri, L.; Passerone, A. An automatic technique for measuring the surface tension of liquid metals. High Temp. Technol. 1989, 7, 82-86. [CrossRef]

19. Sharma, A. An ultraviolet-sterilization protocol for microtitre plates. J. Exp. Microbiol. Immunol. 2012, 16, 144-147.

20. Mosmann, T. Rapid colorimetric assay for cellular growth and survival: Application to proliferation and cytotoxicity assays. J. Immunol. Methods 1983, 65, 55-63. [CrossRef]

21. Berridge, M.V.; Herst, P.M.; Tan, A.S. Tetrazolium dyes as tools in cell biology: New insight into their cellular reduction. Biotechnol. Annu. Rev. 2005, 11, 127-152.

22. Ferrari, M.; Benedetti, A.; Cirisano, F. Superhydrophobic coatings from recycable materials for protection in a real sea environament. Coatings 2019, 9, 303. [CrossRef]

23. Agner, T. Skin Barrier Function. In Current Problems in Dermatology; Itin, P., Jemec, G.B.E., Eds.; Karger Medical and Scientific Publisher: Basel, Switzerland, 2016; Volume 49.

24. Schurer, N.; Kohne, A.; Schliep, V.; Barlag, K.; Goerz, G. Lipid composition and synthesis of HaCaT cells, an immortalized human keratinocyte line, in comparison with normal human adult keratinocytes. Exp. Dermatol. 1993, 2, 179-185. [CrossRef] [PubMed]

25. Samarasinghe, V.; Madan, V. Nonmelanoma skin cancer. J Cutan Aesthet Surg. 2012, 5, 3-10. [CrossRef]

26. OECD. Guidance Document on Good In Vitro Method Practices (GIVIMP); OECD Series on Testing and Assessment, No. 286; OECD Publishing: Paris, France, 2018. [CrossRef]

27. Adan, A.; Kiraz, Y.; Baran, Y. Cell proliferation and cytotoxicity assays. Curr. Pharm. Biotechnol. 2016, 17, 1213-1221. [CrossRef] [PubMed]

28. Kilpi, S.; Lindell, E. Säure-basendissoziation in wasserarmen eisessig-gemischen in beziehung Zu dem wassergehalt. Ann. Acad. Sci. Fennicae II, Chem. 1964, 129, 129.

(C) 2020 by the authors. Licensee MDPI, Basel, Switzerland. This article is an open access article distributed under the terms and conditions of the Creative Commons Attribution (CC BY) license (http://creativecommons.org/licenses/by/4.0/). 